\title{
Design of experiment avenue for development and validation of RP-HPLC- PDA method for determination of apremilast in bulk and in in-house tablet formulation
}

\author{
Suraj R. Chaudhari* (i) and Atul A. Shirkhedkar
}

\begin{abstract}
Background: Apremilast is phosphodiesterase-4 and an immunomodulating agent used for treatment of refractory psoriatic arthritis.

Methods: The reversed-phase high-performance liquid-chromatography method for analysis of apremilast was developed and validated as per ICH guidelines. The separation of apremilast was performed on PrincetonSPHERE Ultima C18 column ( $250 \mathrm{~mm} \times 4.6 \mathrm{~mm}$, i.d., $5 \mu \mathrm{m}$ particle size) with photodiode array detection carried out at $231 \mathrm{~nm}$. A Box-Behnken design with response surface methodology was executed out for optimization of chromatographic conditions of reversed-phase high-performance liquid-chromatography for finished desired chromatographic separation of apremilast from its formulation with less number of experimental trials. Three independent factors, namely methanol composition in the mobile phase, $\mathrm{pH}$ of an aqueous phase, and flow rate, were used to construct a mathematical model and study the effects of these independent factors on responses such as retention time, theoretical plates, and tailing factor.

Results: Optimized experimental conditions for proposed work consists of methanol and water, pH 3.50 adjusted with ortho-phosphoric acid $(70: 30 \% \mathrm{v} / \mathrm{v})$ as a mobile phase at a flow rate $1 \mathrm{ml} / \mathrm{min}$ with a retention time was found to be $5.15 \mathrm{~min}$. Accuracy study was completed at three different levels and was found in the range of $99.44-101.49 \%$.

Conclusion: The 3D response surface graphs revealed that the methanol composition and $\mathrm{pH}$ of an aqueous phase were both most stringent factors affecting the responses. Thus, a new, precise, and accurate HPLC method was developed and validated and can be used for regular analysis of apremilast.
\end{abstract}

Keywords: Apremilast, HPLC, in-house tablets, Box-Behnken design, Validation

\section{Introduction}

Apremilast (APL) is a new therapeutic medicinal agent accepted for the management of psoriasis and psoriasis arthritis (Baumer et al. 2007; Keating 2017). APL is used as orally administered medicine and acts by inhibiting phosphodiesterase 4, which is inhibited intracellularly and responsible for inflammation by lowering the proportion of cAMP; needful for producing the pro- and

\footnotetext{
* Correspondence: chaudharisuraj72@gmail.com

Department of Pharmaceutical Chemistry, R.C. Patel Institute of

Pharmaceutical Education and Research, Dist. Dhule, Shirpur, Maharashtra 424405, India
}

anti-inflammatory mediators (Rajiv 2004; Michalek et al. 2017). APL structurally is (Fig. 1) [N-[2-[(1S)-1-(3-ethoxy-4-methoxyphenyl)-2-methylsulfonylethyl]-1, dioxoisoindol-4-yl] acetamide] (Man et al. 2009). APL is a yellowish white amorphous powder which is insoluble in water and quickly soluble in methanol and acetonitrile. Design of experiments (DOE) has been often executed to optimize analytical methods because of its application, like a decrease in the total number of attempts that need be carried out bringing about less reagent utilization and extensively lower laboratory task. Moreover, DOE permits the buildup of a statistical model that allows appraisal of the 
significance and also statistical acceptation of the various factor effects on the responses being examined and in addition assess the mutual interactions between them (Ferreira et al. 2007). Literature survey acknowledged that several analytical methods have been reported for optimization of chromatographic conditions in high-performance liquid-chromatography (HPLC) methods using Box-Behnken design (Gumustas et al. 2018; De Almeida Borges et al. 2013; Zacharis and Vastardi 2018; Dragomiroiu et al. 2015; Awotwe-Otoo et al. 2012; Bai et al. 2010; Beg et al. 2012; Gomes et al. 2017; Ihssane et al. 2011; Jovanov et al. 2015; Mirza and Tan 2001 and Patel et al. 2017).

Several analytical methods have been developed to estimate APL in pharmaceutical dosage form as well as in biological samples. These methods include HPLC, stability-indicating HPLC, UPLC-MS/MS, and UVspectrophotometry (Xiong et al. 2016; Lonkar et al. 2017a; Chen et al. 2016; Lonkar et al. 2017b; Landge et al. 2017; Ravisankar et al. 2017; Chaudhari and Shirkhedkar 2018; Chaudhari et al. 2018; Lu et al. 2017; Iqbal et al. 2016). Prior art search regarding analytical method for APL depicts that high-performance thinlayer chromatography method (Chaudhari and Shirkhedkar 2018) has been performed using DOE approach for determination of robustness of method as HPLC is more specific and sensitive. The proposed study focuses on development of HPLC method using design of experiment (DOE) approach, followed by validation.

\section{Material and methods}

\section{Chemical and reagents}

Pharmaceutical grade APL was purchased from Sigma-Aldrich (India); HPLC grade methanol, ortho phosphoric acid and double-distilled water were purchased from Merck (Mumbai, India).

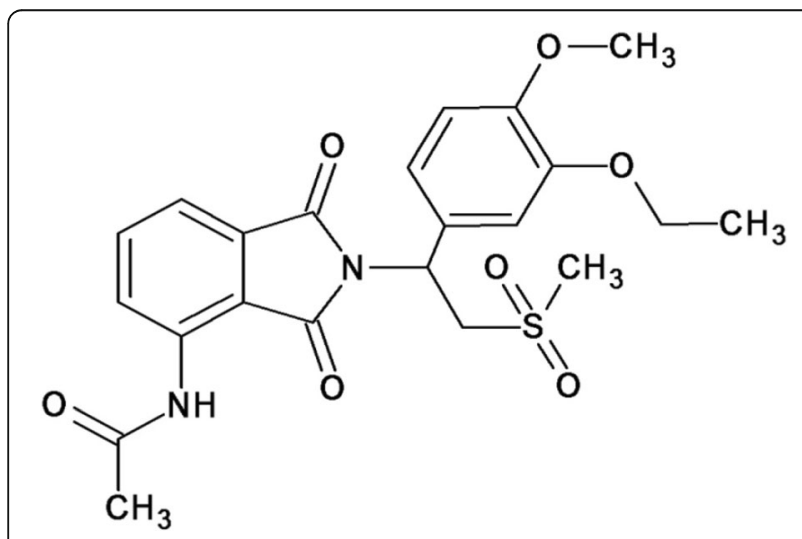

Fig. 1 Chemical structure of apremilast

\section{Instrumentation}

The UFLC HPLC system (Shimadzu Corporation, Japan) consisted of model LC-20 AD binary pump, rehodyne injector with $20 \mu \mathrm{l}$ capacity per injection, CTO-10AS VP column oven compartment, and photodiode array detector (SPD-M20A). The HPLC system was controlled by LC solution software version 1.25. All weighing operations for the proposed analysis were carried out with the help of SHIMADZU AUX-120 analytical balance. Separation of APL was performed on PrincetonSPHERE Ultima $(250 \mathrm{~mm} \times 4.6 \mathrm{~mm} \times 5 \mu \mathrm{m}) \mathrm{C}_{18}$ column from Princeton Chromatography INC, Cranbury South River Road, Cranbury, NJ. The column temperature was maintained at $30^{\circ}$ C. The binary mobile phase consisted of methanol:water (pH 3.50) 70:30\% $v / v$. The mobile phase flow rate was maintained at $1 \mathrm{ml} / \mathrm{min}$. The total analysis run time was less than $7 \mathrm{~min}$ with photodiode array detector (PDA) wavelength set to $231 \mathrm{~nm}$.

\section{Statistical engine}

Design Expert ${ }^{\circ}$ (Version 10.0.7), Stat-Ease Inc., Minneapolis, MN, USA statistical software was utilized for optimization of the method. The remaining calculations for the analysis were performed by Microsoft excel 2010 software (Microsoft, USA).

\section{Preparation of stock solution}

The stock standard solution of APL $(0.1 \mathrm{mg} / \mathrm{ml})$ was prepared by dissolving $10 \mathrm{mg}$ of APL in $100 \mathrm{ml}$ of mobile phase.

\section{Preparation of sample}

As the pharmaceutical formulation of APL is not obtainable in the local Indian market, hence in-house tablets were prepared with $30 \mathrm{mg}$ of APL and frequent excipients. The sample solution was prepared from in-house formulated APL tablets. Accurately weighed power drug equivalent to $30 \mathrm{mg}$, APL was quantitatively transferred into $100 \mathrm{ml}$ volumetric flask dissolved and diluted volume with methanol. The solution was filtered through a $0.45 \mu \mathrm{m}$ filter (Millifilter, Milford, MA, USA). From the filtrate, an appropriate volume of solution was diluted to get a final concentration $6 \mu \mathrm{g} / \mathrm{ml}$ using mobile phase.

\section{Chromatographic conditions}

Chromatographic separation of APL was carried out on PrincetonSPHERE Ultima $(250 \mathrm{~mm} \times 4.6 \mathrm{~mm} \times 5 \mu \mathrm{m}) \mathrm{C}_{18}$ analytical column at ambient temperature; mobile phase consisted of methanol:water $(70: 30 \% v / v, \mathrm{pH} 3.5)$ and the $\mathrm{pH}$ of aqueous phase were adjusted with orthophosphoric acid. Before the analysis, mobile phase was filtered through a $0.2 \mu \mathrm{m}$ Ultipor $\mathrm{N}_{66}$ Nylon 6, 6 membrane and sonicated mobile phase for $25 \mathrm{~min}$. A constant volume of 
$20 \mu \mathrm{l}$ was an injected and the chromatogram was monitored at a detection wavelength of $231 \mathrm{~nm}$.

\section{Optimization of RP-HPLC-PDA method}

Initially, trial and error method was applied to gain knowledge about the method performance and recognition of various vital independent parameters and its effect on dependent variables. The prime importance of developing RP-HPLC method mainly separates the APL from its degradants and recommended that the resolution is greater than 2.0. Further, the Box-Behnken design with response surface was employed for optimization of experimental conditions of the method. In the present investigation, experiments were planned and conducted according to the Box-Behnken design. The independent factors used in the present investigation had three levels resulting in total 17 experimental runs was shown in Table 1 . The stated value for all three factors, namely (A) methanol composition, $\mathrm{pH}$ of aq. mobile phase, and flow rate, were $70 \%, 3.5 \mathrm{pH}$, and $1 \mathrm{ml} / \mathrm{min}$. A Box-Behnken statistical screening design was used to optimize the compositional parameters and to evaluate quadratic effects of the methanol composition in the mobile phase, $\mathrm{pH}$ of aq. mobile phase, and flow rate on the retention time (Rt), theoretical plates, and tailing factor. The linear polynomial equations are generated from ANOVA, depicted below.

Table 1 Box-Behnken design experimental runs

\begin{tabular}{|c|c|c|c|c|c|c|}
\hline \multirow[t]{2}{*}{ Runs } & \multicolumn{3}{|l|}{ Factors } & \multicolumn{3}{|l|}{ Responses } \\
\hline & $\begin{array}{l}\text { Methanol } \\
\text { composition } \\
(\%)\end{array}$ & $\begin{array}{l}\mathrm{pH} \text { of aq. } \\
\text { phase }\end{array}$ & $\begin{array}{l}\text { Flow rate } \\
(\mathrm{ml} / \mathrm{min})\end{array}$ & $\begin{array}{l}\text { Retention } \\
\text { time }\end{array}$ & $\begin{array}{l}\text { Theoretical } \\
\text { plates }\end{array}$ & $\begin{array}{l}\text { Tailing } \\
\text { factor }\end{array}$ \\
\hline 1 & 60 & 3.5 & 0.8 & 7.56 & 2235 & 1 \\
\hline 2 & 70 & 4 & 1.2 & 5.85 & 2466 & 1.35 \\
\hline 3 & 70 & 3.5 & 1 & 5.32 & 2205 & 1 \\
\hline 4 & 70 & 3.5 & 1 & 5.15 & 2257 & 1.04 \\
\hline 5 & 70 & 3.5 & 1 & 5.15 & 2257 & 1.04 \\
\hline 6 & 80 & 3 & 1 & 4.12 & 2136 & 0.85 \\
\hline 7 & 80 & 4 & 1 & 4.13 & 2498 & 1.36 \\
\hline 8 & 80 & 3.5 & 0.8 & 5.86 & 2245 & 1.03 \\
\hline 9 & 60 & 3 & 1 & 7.45 & 2178 & 0.86 \\
\hline 10 & 80 & 3.5 & 1.2 & 5.96 & 2305 & 1.05 \\
\hline 11 & 70 & 3 & 0.8 & 5.12 & 2139 & 0.85 \\
\hline 12 & 70 & 4 & 0.8 & 5.96 & 2496 & 1.41 \\
\hline 13 & 60 & 4 & 1 & 7.55 & 2503 & 1.43 \\
\hline 14 & 70 & 3.5 & 1 & 5.18 & 2265 & 1.05 \\
\hline 15 & 70 & 3 & 1.2 & 6.23 & 2145 & 0.95 \\
\hline 16 & 70 & 3.5 & 1 & 5.15 & 2245 & 1.05 \\
\hline 17 & 60 & 3.5 & 1.2 & 6.98 & 2198 & 1.1 \\
\hline
\end{tabular}

$$
\begin{aligned}
Y= & b_{\mathrm{o}}+b_{1} x_{1}+b_{2} x_{2}+b_{3} x_{3}+b_{12} x_{1} x_{2}+b_{13} x_{1} x_{3} \\
& +b_{23} x_{2} x_{3}+b_{11} x^{2}{ }_{2}+b_{22} x^{2}{ }_{2}+b_{33} x^{2}{ }_{3}
\end{aligned}
$$

Where ' $y$ ' is the measured response (dependent variable) connected with each factor level combination; ' $b_{0}$ ' symbolizes the polynomial equation intercept representing average arithmetic mean of all quantitative outcomes of 17 runs and ' $b_{1}-b_{33}$ ' is regression coefficients computed from the observed experimental values of ' $y$ ', ' $y_{1}$ ', ' $y_{2}$ ', ' $x_{1}$ ', ' $x_{2}$ ', and ' $x_{3}$ ' represent the coded levels of independent variables. Where $x_{1}$ : methanol composition in mobile phase, $x_{2}: \mathrm{pH}$ of mobile phase, $x_{3}$ : flow rate respectively, for $x_{1}, x_{2}$, and $x_{3}$. The considered responses were retention time $\left(y_{1}\right)$, theoretical plates $\left(y_{2}\right)$, and tailing factor $\left(y_{3}\right)$. In this situation, methanol volume was selected as $60 \%$ to $80 \%$. While $\mathrm{pH}$ of mobile phase was fixed between 3 and 4 appropriately, similarly flow rate was put up between 0.8 to $1.2 \mathrm{ml} / \mathrm{min}$ respectively. The statistical analysis was performed using Design Expert ${ }^{\circ}$ (Version 10.0.7), Stat-Ease, Inc. 2021 East Hennepin Ave., Suite 480 Minneapolis, MN 55413, USA.

\section{Validation of method}

The proposed method was validated in accordance with the International Conference of Harmonisation (2005), for various parameters like system suitability, $\%$ recovery, precision, detection and quantification limit, robustness, ruggedness specificity, and force degradation study.

\section{System suitability}

In order to perform system suitability studies, six replicate injections of $10 \mu \mathrm{g} / \mathrm{ml}$ standard solution of APL was injected and analyzed with HPLC. The results of system suitability parameters were studied for capacity factor, tailing factor, theoretical plate, and peak area.

\section{Linearity study}

The linearity study of the proposed method was examined as per the International Conference on Harmonization (ICH) guidelines. The calibration curve for APL was obtained in the concentration range of $2-12 \mu \mathrm{g} / \mathrm{ml}$; further, the calibration curve was constructed within peak area versus concentration. The regression equation was $Y=$ $10,304 x+13,583$ and regression coefficient $r^{2}=0.998$.

\section{Accuracy}

The accuracy of a commenced investigation was appraised by standard addition methods, where a known amount of the standard was added in three different levels, i.e., 80, 100, and $120 \%$ to in-house tablet formulation of APL and analyzed by the commenced method in a set of three. The \% recovery studies for APL were 
carried out by spiking three different amount of APL standard $(80,100$, and $120 \%)$ to the in-house tablet formulation. The \% recovery of APL was estimated for each level.

\section{Precision}

The precision of the commenced analysis was evaluated by carrying out by intra-day and inter-day precision. The three sets of three different concentrations, i.e., 4,8 , and $10 \mu \mathrm{g} / \mathrm{ml}$, of APL was analyzed on the same for repeatability and continuous 3 days for intermediate precision.

\section{Detection limit and quantification limit}

The detection limit and quantification limit of the present study were assessed from the standard deviation of the peak area and the slope of the linearity curve of APL. The detection limit was communicated as a signal-to-noise ratio of $3: 1$, while quantification limit was indicated as signal-to-noise ratio 10:1; as a result of the detector response. The different concentrations of $2-4 \mu \mathrm{g} / \mathrm{ml}$ were prepared and tested. The $\%$ RSD was calculated.

\section{Specificity}

Chromatogram of in-house tablet mixture was compared with the standard as well as with blank to revel obstruction of excipients. But the chromatogram of the mixture was not showing any eloquent interference at the retention time of APL.

\section{Robustness}

Robustness can be interpreted as the capability to reproduce the (analytical) method in diverse laboratories or under different conditions without the occurrence of unexpected differences in the obtained results, and a robustness test as an experimental set-up to evaluate the robustness of a method. To check the capability of the proposed method, different factors were knowingly changed like a change in column oven temperature $\left(25-35{ }^{\circ} \mathrm{C}\right)$, detection wavelength (228-232 $\mathrm{nm})$, and injection volume (15$25 \mu \mathrm{l})$.

\section{Results and discussion}

Optimization and development of RP-HPLC-PDA method using Box-Behnken design

In proposed investigation, 17 experimental runs were performed and analyzed for obtained results of retention time, theoretical plates, and tailing factors in accord with the Box-Behnken design. Further investigation was performed using response surface methodology (RSM) to evaluate the relationship between the dependent responses and independent variables (factors) using obtained data was reported in Table 1. The model was also validated by analysis of variance (ANOVA) using design expert software, and the results are as presented in Table 2. Based on press value, a quadratic model was selected for responses such as retention time, theoretical plates, and tailing factor of APL. The significant effects showed $p$ value less than 0.05 , while the low standard deviation (\% C.V) and a high adjusted $R$-square value indicated a good relationship between the experimental data and those of the fitted model. The predicted $R$-square value was in acceptable concordance with the adjusted $R$-square value for all responses.

The final equation in terms of actual components and factors which can be used to make predictions about the response for given levels of each factor,

$$
\begin{aligned}
\text { Retention time }= & +5.19-1.18 x_{1}+0.071 x_{2}+0.065 x_{3} \\
& -0.023 x_{1} x_{2}+0.17 x_{1} x_{3}-0.31 x_{2} x_{3} \\
& +0.75 x^{2}{ }_{1}-0.089 x^{2}{ }_{2}+0.69 x^{2}{ }_{3}
\end{aligned}
$$

$$
\begin{aligned}
\text { Theoretical plates }= & +2245.80+8.75 x_{1}+170.62 x_{2} \\
& -0.13 x_{3}+9.25 x_{1} x_{2}+24.25 x_{1} x_{3} \\
& +9.00 x_{2} x_{3}+8.60 x^{2}{ }_{1}+74.35 x^{2}{ }_{2} \\
& -8.65 x^{2}{ }_{3}
\end{aligned}
$$

$$
\begin{aligned}
\text { Tailing factor }=1.04 & -0.012 x_{1}+0.25 x_{2}+0.020 x_{3} \\
& -0.015 x_{1} x_{2}-0.020 x_{1} x_{3}-0.040 x_{2} x_{2} \\
& -3.000 \mathrm{E}-003 x^{2}{ }_{1} \\
& +0.092 x^{2}{ }_{2}+0.612 x^{2}{ }_{3}
\end{aligned}
$$

A positive value represents an effect that favors optimization while a negative value indicates an inverse relationship between the factors and the responses. 3-D

Table 2 ANOVA results

\begin{tabular}{llllllllll}
\hline Responses & \pm SD & Mean & \% C. V. & Press & $r^{2}$ & Adjusted $R$-square & Predicted $R$-square & Adequate precision & $p$ value \\
\hline Retention time & 0.58 & 5.81 & 9.96 & 37.14 & 0.873 & 0.7103 & 1.0107 & 7.437 & 0.0188 \\
Theoretical plates & 29.11 & 2280.76 & 1.28 & $61,942.00$ & 0.977 & 0.9491 & 0.7675 & 17.25 & 0.0001 \\
Tailing factor & 0.026 & 1.08 & 2.41 & 0.051 & 0.9917 & 0.9810 & 0.9105 & 29.46 & 0.0001 \\
\hline
\end{tabular}




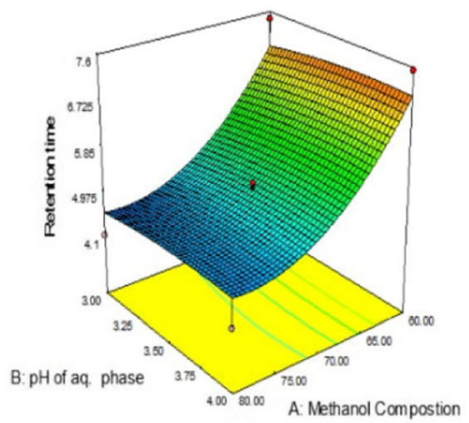

(a)

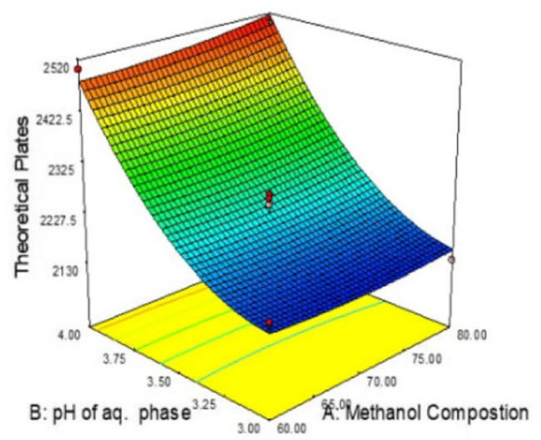

(d)

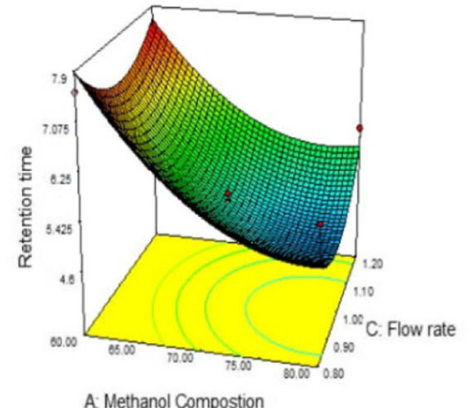

(b)

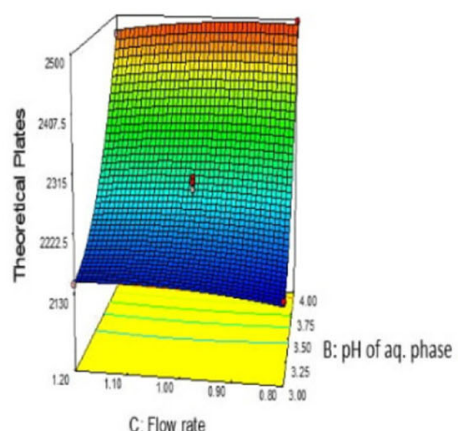

(e)

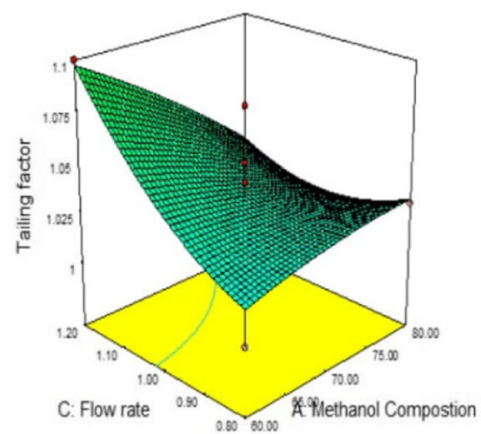

(g)

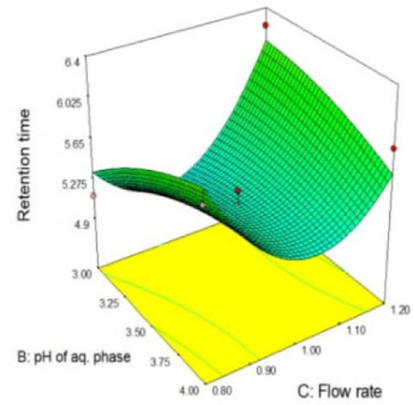

(c)

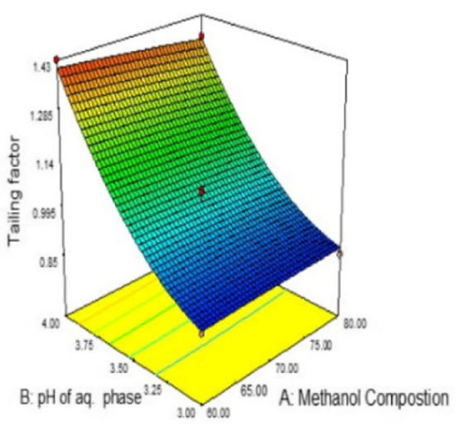

(f)

Fig. 2 3D RSM plots for retention time, theoretical plates, and tailing factor

response surface plots revealed the effect of factors such as methanol composition in a mobile phase, $\mathrm{pH}$ of aq. mobile phase, and flow rate of HPLC system on the responses retention time, theoretical plates, and tailing factor. The representative plots for responses are presented in Fig. 2, in which the interaction between variables factors $A$ and $B$ and their mutual dependence is clearly observed, while factor $\mathrm{C}$ is kept constant. Figure 2a indicates that methanol composition in mobile phase showed a prominent effect on retention time. The retention time is increased with decreased in methanol composition in the mobile phase and increased or decreased in $\mathrm{pH}$ of aqueous mobile phase; there is not show any effect on retention time. The retention time decreased with increased in methanol composition and increased with decreased in methanol composition in mobile phase while flow rate showed the irrelevant effect on retention time showed in Fig. 2b. The increased flow rate with increased retention time, while $\mathrm{pH}$ of aqueous mobile phase showed the inappropriate effect on retention time showed in Fig. 2c-e confirmed that the theoretical plates of column increased with increased in $\mathrm{pH}$ of aqueous mobile phase, while methanol composition in the mobile phase and flow rate showed an insignificant effect on theoretical plates of the column. The increased in tailing factor with increased in $\mathrm{pH}$ of aqueous mobile phase and the increased in flow rate with increased in tailing factor, while methanol composition did 


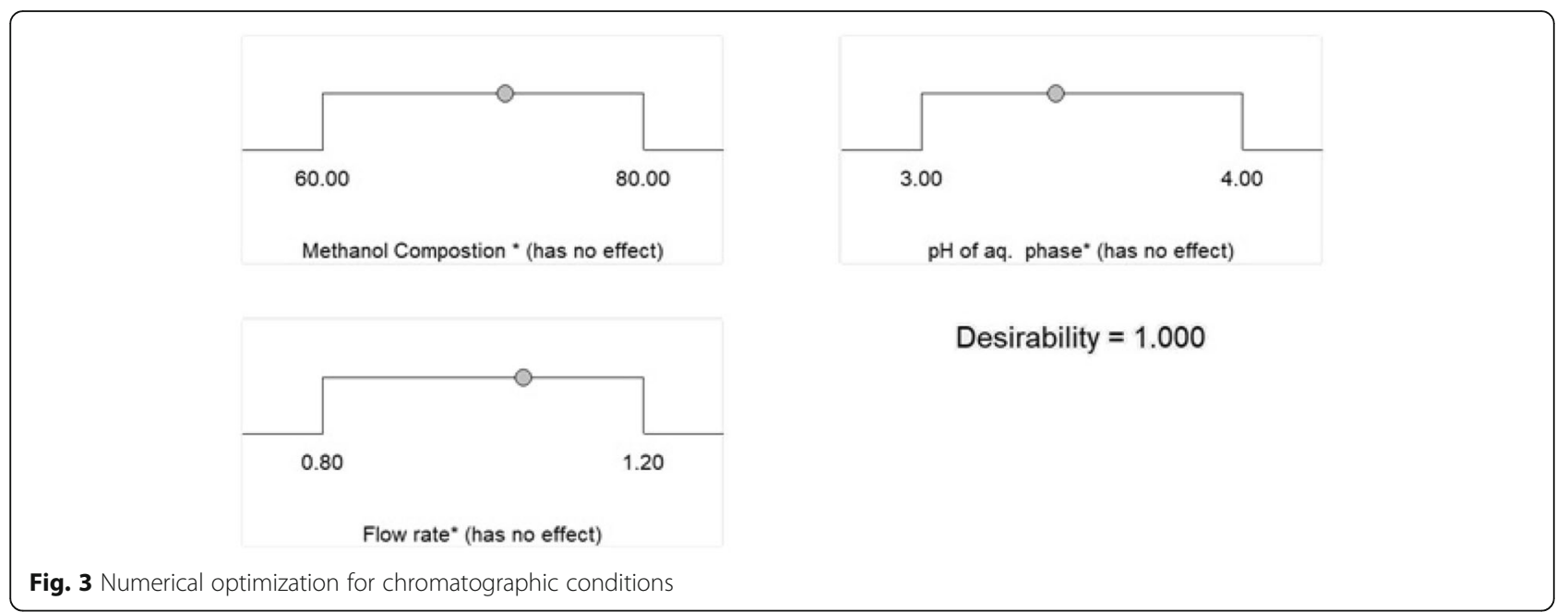

not show any significant effect on tailing factor was shown in Fig. 2f, g.

During numerical optimization shown in Fig. 3, the Box-Behnken design presented 30 solutions for optimized chromatographic conditions, but the solutions were reduced by setting the goals. Different limitations for factors and responses were sets and one solution was selected for optimization of chromatographic conditions. It was clearly shown that the experiential value of chromatographic condition was very nearer to the anticipated value. Hence the optimized chromatographic conditions, methanol composition (70\%), flow rate $(1 \mathrm{ml} / \mathrm{min})$, and $\mathrm{pH}$ of aqueous mobile phase (3.5), respectively the chromatogram of APL were shown in Fig. 4.

\section{Validation}

The optimized chromatographic conditions were aggrandized applied to validation of assertion for the system suitability, linearity, accuracy, precision, sensitivity, selectivity and robustness.

\section{System suitability}

System suitability tests are referred for assessing chromatographic system before the sample analysis can start. The system suitability estimated by six represents analysis of $10 \mu \mathrm{g} / \mathrm{ml}$ concentration of APL. The system suitability testing was evaluated and \% RSD (percent relative standard deviation) was commencing less than $2 \%$ confine demonstrating appropriateness of strategy advancement. The results were shown in Table 3.

\section{Linearity}

The calibration curve for APL was constructed and the linearity was obeyed in the given concentration range of $2-12 \mu \mathrm{g} / \mathrm{ml}$ of APL which depicts excellent correlation coefficient $r^{2}=0.998$.

\section{Accuracy}

The accuracy study was examined by the standard addition method testing the three unequal concentrations 3.2, 4, and $4.8 \mu \mathrm{g} / \mathrm{ml}$ of APL. The \% recovery was found in the range of $99.44-101$. Then, $49 \%$ with $\%$ RSD values were within the range $0.71-0.88$ and fulfilling the acknowledgment criteria for the examination.

\section{Precision}

For the assessment of precision of the method, three distinct concentrations of APL were determined by assay at distinctive time period on the same day and by alteration for the three successive days (intra-day and inter-day precision) according to the ICH guidelines. The proposed developed method displayed the \% RSD for intra-day and inter-day precision were in the range of $0.15-0.77$ and $0.17-0.78 \%$. The results of precision study were epitomized in Table 4 .

\section{Sensitivity}

Sensitivity of proposed method was determined using the formulas $\mathrm{DL}=3.3 \alpha / \mathrm{S}$ and $\mathrm{QL}=10 \alpha / \mathrm{S}$. The detection limit and quantification limit (DL and QL) were found to be 0.015 and $0.416 \mu \mathrm{g}$, respectively for APL. 


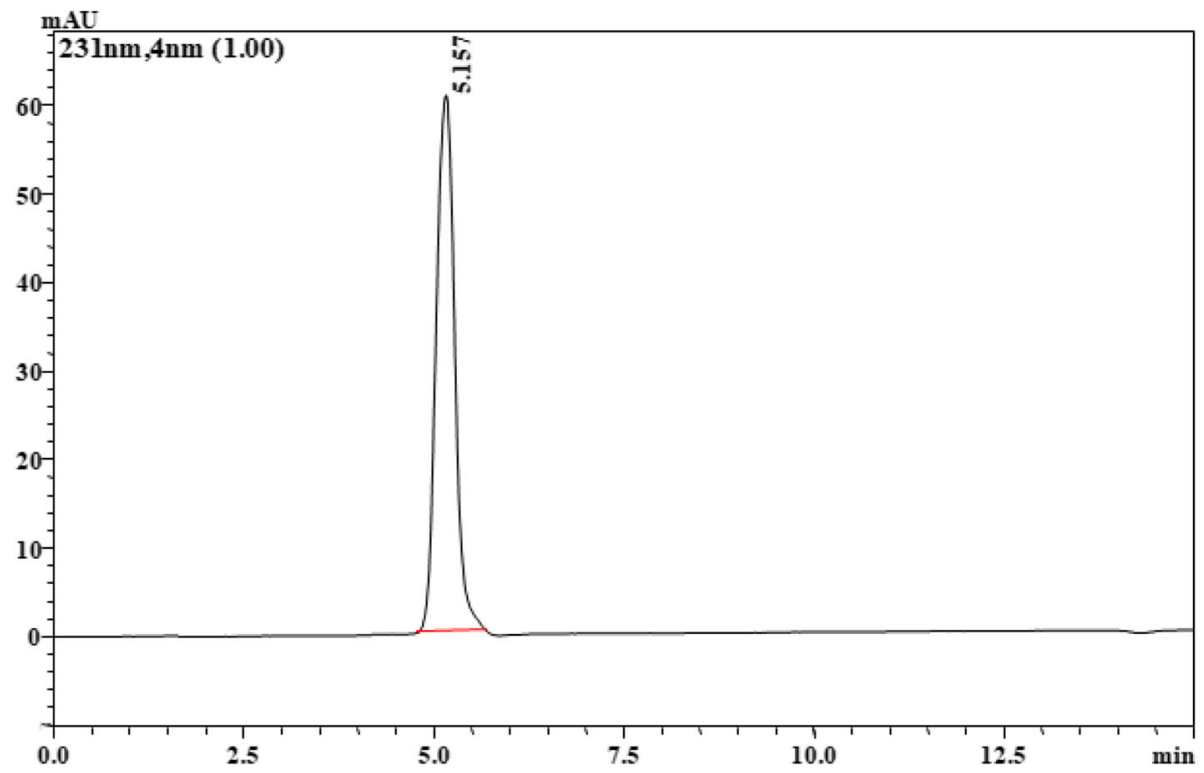

Fig. 4 Chromatogram of apremilast

\section{Robustness}

The robustness of the present analysis was performed by executing small intended modification in chromatographic circumstances. The robustness study of commenced method were evaluated using different factors such as column oven temperature (25-35 $\left.{ }^{\circ} \mathrm{C}\right)$, detection wavelength $(228-232 \mathrm{~nm})$, and injection volume $(15-25 \mu \mathrm{l})$. The influence of each of the factors was predicated and none of the factors go beyond the utmost and in this way demonstrated the studied independent variables did not influence the results. Besides, the commence method was found to be specific as the excipients did not show a bit of interference at a retention time of APL. The summary of the proposed method was shown in Table 5.

\section{Analysis of in-house tablet formulation}

The proposed RP-HPLC-PDA method was used to estimate APL in prepared in-house tablet formulation. The

Table 3 System suitability results

\begin{tabular}{ll}
\hline Parameters & Estimates \\
\hline Retention time (min) & 5.15 \\
Theoretical plates & 2257 \\
Tailing factor & 1.045 \\
Capacity factor & 1.063 \\
\hline
\end{tabular}

$\%$ amount of drug found in triplicate analysis for APL was found to be $98.85 \pm 0.13 \%$, respectively. In the future, the developed method can be frequently used for analysis of APL.

\section{Comparison of proposed method with reported method}

The assay and \% recovery studies of APL using proposed method was compared with reported RP-HPLC method (Lonkar et al. 2017b). On the basis of results obtained for assay and \% recovery studies, proposed method is comparable with the existing reported method (Table 6).

Table 4 Precision study

\begin{tabular}{llll}
\hline $\begin{array}{l}\text { Standard concentration } \\
(\mu \mathrm{g} / \mathrm{ml})\end{array}$ & $\begin{array}{l}\text { Amount found } \\
(\mu \mathrm{g} / \mathrm{ml})\end{array}$ & $\begin{array}{l}\text { \% Amount found } \\
(\mu \mathrm{g} / \mathrm{ml}) \\
(n=3)\end{array}$ & \% RSD \\
\hline $\begin{array}{llll}\text { Intra-day precision } \\
4\end{array}$ & 3.98 & 99.69 & 0.15 \\
8 & 8.07 & 100.89 & 0.31 \\
10 & 10.14 & 101.44 & 0.77 \\
Inter-day precision & & & \\
4 & 3.94 & 98.61 & 0.17 \\
8 & 8.07 & 100.87 & 0.82 \\
10 & 9.56 & 98.63 & 0.98 \\
\hline$n$ number of determinations & &
\end{tabular}


Table 5 Summary of regression, validation, and in-house tablet assay parameters for proposed RP-HPLC-PDA method

\begin{tabular}{ll}
\hline Validation parameters & Results \\
\hline Regression coefficient & 0.998 \\
Slope & 13583 \\
Intercept & $10304 x$ \\
Linearity range $(\mu \mathrm{g} / \mathrm{ml})$ & $2-12$ \\
Intra-day precision $(n=3, \mathrm{RSD}, \%)$ & $0.15-0.77$ \\
Inter-day precision $(n=3, \mathrm{RSD}, \%)$ & $0.17-0.98$ \\
Repeatability $(n=3, \mathrm{RSD}, \%)$ & 1.66 \\
Accuracy & $99.44-100.49$ \\
DL ( $\mu \mathrm{g})$ & 0.015 \\
QL ( $\mu \mathrm{g})$ & 0.41 \\
Ruggedness & \\
Analysts I $(n=3, \mathrm{RSD}, \%)$ & 1.59 \\
Analysts $I$ ( $n=3, \mathrm{RSD}, \%)$ & 1.27 \\
Robustness & Robust \\
Specificity & Specific \\
In-house tablet assay & $98.85 \pm 0.13$ \\
\hline
\end{tabular}

$n$ number of determinations

\section{Conclusion}

A precise, accurate, rugged, cost-effective, and robust RP-HPLC method using Box-Behnken principles has been developed for estimation of APL in bulk and in in-house tablet dosage form. By employing the DOE approach, Box-Behnken design permitted assessment of the independent factors simultaneously with addition of mutual interactions between the factors in order to optimize experimental conditions. According to the response surface plots, the methanol composition was found to be the most inflexible factor for retention time. The $\mathrm{pH}$ of aqueous mobile phase was found to be a more deliberate factor for tailing factor as well as for theoretical plates. It is understood that the utilization of design of experiment approach is an adaptable practice to decrease the total experimental runs required for the optimization and development of RP-HPLC method can create most extreme data within a short duration of time. The excellent \% recovery

Table 6 Comparison of proposed method with the reported methods for analysis of APL (Lonkar et al. 2017a, 2017b)

\begin{tabular}{lll}
\hline Parameters for comparison & Proposed method & Reported method \\
\hline Assay & $98.85 \%$ & $99.14 \%$ \\
\% Recovery & $99.44-100.49$ & $98.80-99.28$ \\
\hline
\end{tabular}

of a drug shows that the excipients present in the tablet formulation have no obstruction in the determination of APL. The optimized chromatographic conditions of the proposed method confirmed that the proposed study was accurate, precise, rugged, and robust. Therefore, the developed method can be used for the regular analysis of APL in bulk and in a pharmaceutical formulation. The proposed method was also compared with the reported method and found comparable.

\section{Abbreviations}

APL: Apremilast; BBD: Box-Behnken design; DL and QL: Detection limit and quantification limit; DOE: Design of experiments; HPLC: High-performance liquidchromatography; ICH: International Conference on Harmonization; PDA: Photodiode array detector; RSM: Response surface methodology; Rt: Retention time

\section{Acknowledgments}

We acknowledge our sincere thanks to R. C. Patel Institute of Pharmaceutical Education and Research Shirpur, Dist: Dhule (MS) 425405.

Funding

Not applicable

Availability of data and materials

Not applicable

\section{Authors' contributions}

SRC executed experimental and method development work. AAS organized a preliminary draft of the article. Both authors read and approved the final manuscript.

\section{Competing interests}

The authors declare that they have no competing interests.

\section{Publisher's Note}

Springer Nature remains neutral with regard to jurisdictional claims in published maps and institutional affiliations.

Received: 20 November 2018 Accepted: 11 February 2019 Published online: 27 February 2019

\section{References}

Awotwe-Otoo D, Agarabi C, Faustino PJ, Habib MJ, Lee S, Khan MA, Shah RB. Application of quality by design elements for the development and optimization of an analytical method for protamine sulfate. J Pharm Biomed Anal. 2012;62:61-7. https://doi.org/10.1016/j.jpba.2012.01.002.

Bai XL, Yue TL, Yuan YH, Zhang HW. Optimization of microwave-assisted extraction of polyphenols from apple pomace using response surface methodology and HPLC analysis. J Sep Sci. 2010;33:3751-8. https://doi.org/ 10.1002/jssc.201000430.

Baumer W, Hoppmann J, Rundfeldt C, Kietzmann M. Highly selective phosphodiesterase 4 inhibitors for the treatment of allergic skin diseases and psoriasis. Inflamm Allergy Drug Targets. 2007;6:17-26. https://doi.org/10.2174/ 187152807780077318.

Beg S, Kohli K, Swain S, Hasnain MS. Development and validation of RP-HPLC method for quantitation of amoxicillin trihydrate in bulk and pharmaceutical formulations using Box-Behnken experimental design. J Liq Chromatogr Relat Technol. 2012;35:393-406. https://doi.org/10.1080/10826076.2011.601493.

Chaudhari SR, Patil AS, Shirkhedkar AA. Studies on derivative spectroscopy and area under curve UV-spectrophotometric methods for estimation of Apremilast in bulk and in-house Tablets. Asian J Pharm Res. 2018;8:11-6. https://doi.org/10.5958/2231-5691.2018.00003.5.

Chaudhari SR, Shirkhedkar AA. Application of Box-Behnken Design for Validation of high-performance thin-layer chromatography/densitometry method for robustness determination of Apremilast in bulk and in-house tablets. Pharm Methods. 2018;9:9-15. https://doi.org/10.5530/phm.2018.1.3. 
Chen L-g, Wang Z, Wang S, Li T, Pan Y, Lai X. Determination of apremilast in rat plasma by UPLC-MS-MS and its application to a pharmacokinetic study. J Chromatogr Sci. 2016;54:1336-40. https://doi.org/10.1093/chromsci/bmw072. De Almeida Borges VR, Ribeiro AF, de Souza Anselmo C, Cabral LM, de Sousa VP. Development of a high performance liquid chromatography method for quantification of isomers $\beta$-caryophyllene and a-humulene in copaiba oleoresin using the Box-Behnken design. J Chromatogr B. 2013;940:35-41. https://doi.org/10.1016/j.jchromb.2013.09.024.

Dragomiroiu GTAB, Cimpoieşu ADINA, Ginghina O, Baloescu C, Barca M, Popa DE, Ciobanu AM, Anuta V. The development and validation of a rapid HPLC method for determination of piroxicam. Farmacia. 2015;63:123-31.

Ferreira SC, Bruns RE, Ferreira HS, Matos GD, David JM, Brandao GC, da Silva EP, Portugal LA, Dos Reis PS, Souza AS, Dos Santos WNL. Box-Behnken design: an alternative for the optimization of analytical methods. Anal Chim Acta. 2007:597:179-86. https://doi.org/10.1016/j.aca.2007.07.011.

Gomes SV, Portugal LA, dos Anjos JP, de Jesus ON, de Oliveira EJ, David JP, David JM. Accelerated solvent extraction of phenolic compounds exploiting a BoxBehnken design and quantification of five flavonoids by HPLC-DAD in Passiflora species. Microchem J. 2017;132:28-35. https://doi.org/10.1016/j. microc.2016.12.021

Gumustas M, Caglayan MG, Onur F, Ozkan SA. Simultaneous determination and validation of emtricitabine, rilpivirine and tenofovir from biological samples using LC and CE methods. Biomed Chromatogr. 2018;32:4158. https://doi. org/10.1002/bmc.4158.

Ihssane B, Charrouf M, Abourriche A, Abboud Y, Bouabidi A, Bennamara A, Saffaj T. Optimization and validation of a new high-performance liquid chromatographic method for analysis of acetazolamide in tablets using BoxBehnken statistical experiment design. Acta Chromatogr. 2011;23:41-57. https://doi.org/10.1556/AChrom.23.2011.1.2.

International Conference of Harmonisation. Q2 (R1), validation of analytical procedures: text and methodology. In: International Conference on Harmonization, Geneva; 2005. p. 11-12

Iqbal M, Ezzeldin E, Al-Rashood ST, Imam F, Al-Rashood KA. Determination of apremilast in rat plasma by UPLC-MS/MS in ESI-negative mode to avoid adduct ions formation. Bioanalysis. 2016;8:1499-508. https://doi.org/10.4155/ bio-2016-0098.

Jovanov P, Guzsvány V, Lazić S, Franko M, Sakač M, Šarić L, Kos J. Development of HPLC-DAD method for determination of neonicotinoids in honey. J Food Compos Anal. 2015;40:106-13. https://doi.org/10.1016/j.jfca.2014.12.021.

Keating GM. Apremilast: a review in psoriasis and psoriatic arthritis. Drugs. 2017; 77:459-72. https://doi.org/10.1007/s40265-017-0709-1.

Landge SB, Dahale SB, Jadhav SA, Solanki PV, Bembalkar SR, Mathad VT. Development and validation of stability indicating rapid RP-LC method for determination of process and degradation related impurities of Apremilast, an anti-inflammatory drug. Am J Anal Chem. 2017:8:380. https://doi.org/10. 4236/ajac.2017.86029.

Lonkar N, Dole M, Sawant S. Development and validation of UVspectrophotometric method for the estimation of apremilast in bulk form by absorbance maxima method. W. J Pharm Pharm Sci. 2017b;6:758-66. https:// doi.org/10.20959/wjpps20177-9437.

Lonkar N, Sawant S, Dole M. Development and validation of stability indicating RP-HPLC method for the estimation of apremilast by forced degradation studies. W. J Pharm Pharm Sci. 2017a;6:1493-502. https://doi.org/10.20959/ wjpps20174-8934.

Lu Y, Shen X, Hang T, Song M. Identification and characterization of processrelated substances and degradation products in apremilast: process optimization and degradation pathway elucidation. J Pharm Biomed Anal. 2017;141:70-8. https://doi.org/10.1016/j.jpba.2017.03.067.

Man HW, Schafer P, Wong LM, Patterson RT, Corral LG, Raymon H, et al. Discovery of (S)-N-\{2-[1-(3-ethoxy-4-methoxyphenyl)-2-methanesulfonylethyl]1, 3-dioxo-2, 3-dihydro-1 H-isoindol-4-yl\} acetamide (apremilast), a potent and orally active phosphodiesterase 4 and tumor necrosis factor-a inhibitor. J Med Chem. 2009;52:1522-40. https://doi.org/10.1021/jm900210d.

Michalek I, Loring B, John SA. Systematic review of worldwide epidemiology of psoriasis. J Eur Acad Dermatol Venereol. 2017;31:205-12. https:/doi.org/10.1111/jdv.13854.

Mirza T, Tan HS. Determination of captopril in pharmaceutical tablets by anionexchange HPLC using indirect photometric detection; a study in systematic method development. J Pharm Biomed Anal. 2001;25:39-52. https://doi.org/ 10.1016/S0731-7085(00)00462-3.

Patel KG, Patel AT, Shah PA, Gandhi TR. Multivariate optimization for simultaneous determination of aspirin and simvastatin by reverse phase liquid chromatographic method using aqbd approach. Bull F Pharm Cairo Uni. 2017;55:293-301. https://doi.org/10.1016/j.bfopcu.2017.08.003.

Rajiv J. Immunopathogenesis of psoriasis. Ind J Dermatol Venereol Leprol. 2004;70:10-2.

Ravisankar P, Sulthana MS, Babu PS. Development and validation of stabilityindicating UV spectrophotometric method for determination of Apremilast in bulk and pharmaceutical dosage form. Ind J Res Pharm Biotechnol. 2017;5:47.

Xiong K, Ma X, Cao N, Liu L, Sun L, Zou Q, et al. Identification, characterization and HPLC quantification of impurities in apremilast. Anal Methods. 2016;8: 1889-97. https://doi.org/10.1039/C5AY01759A.

Zacharis CK, Vastardi E. Application of analytical quality by design principles for the determination of alkyl p-toluenesulfonates impurities in Aprepitant by HPLC validation using total-error concept. J Pharm Biomed Anal. 2018;150: 152-61. https://doi.org/10.1016/j.jpba.2017.12.009.

\section{Submit your manuscript to a SpringerOpen ${ }^{\circ}$ journal and benefit from:}

- Convenient online submission

Rigorous peer review

- Open access: articles freely available online

- High visibility within the field

- Retaining the copyright to your article

Submit your next manuscript at $>$ springeropen.com 